\title{
Solution for Injection in Dose-Dispenser Cartridge
}

National Cancer Institute

\section{Source}

National Cancer Institute. Solution for Injection in Dose-Dispenser Cartridge. NCI

Thesaurus. Code C149915.

Medicinal product consisting of a solution for injection presented in a dose-dispenser cartridge. 